\title{
Heavy metal elimination from industrial wastewater using natural substrate on pitcher irrigation
}

\author{
Payam Najafi $^{1} \cdot$ Kamran Asgari $^{2} \cdot$ Najmeh Samadi $^{3}$
}

Received: 18 May 2016/Accepted: 18 October 2016/Published online: 14 November 2016

(C) The Author(s) 2016. This article is published with open access at Springerlink.com

\begin{abstract}
Combination of pitcher irrigation with drip irrigation system could be resulted in prolonging the secondary treatment period, as it could be an efficient system in which municipal and industrial wastewater can be treated and heavy metals can be reduced. For this purpose, an experiment was conducted with three treatments [clay pitcher included natural zeolite Clinoptilolite (NZ), perlite (P) and vermiculite $(\mathrm{V})$ ] which filled half of the volume of a clay pitcher with five replications for each treatments. Beside each tree, one pitcher was placed at $50 \mathrm{~cm}$ depth. The soil of each hole was initially sampled, sealed, and transported to the laboratory. The pitchers were irrigated with treated industrial wastewater (from steel factory) 60 times (1500 cc per each irrigation event) over a period of six months. At the end of experiment period, the pitchers were removed and samples were taken from the substrate inside each pitcher and from the soil near the walls and bottoms of the holes. The sealed samples were transported to the laboratory for analyzing heavy metals $(\mathrm{Fe}, \mathrm{Cd}, \mathrm{Cr}$, $\mathrm{Cu}, \mathrm{Pb}, \mathrm{Mn}$, and $\mathrm{Zn}$ ) using an atomic absorption
\end{abstract}

Payam Najafi

Payam.najafi@gmail.com

Kamran Asgari

Kamran.Asgari@stu.sku.ac.ir

Najmeh Samadi

najmeh@ualberta.ca

1 Department of water engineering, Faculty of Agriculture, Islamic Azad University, Isfahan (Khorasgan) Branch, Isfahan, Iran

2 Department of Soil Science, Faculty of Agriculture, Shahrekord University, Shahrekord, Iran

3 Department of Renewable Resources, University of Alberta, Edmonton, Canada spectrophotometer. The results showed that the used substrates in this experiment have high ability to absorb some heavy metals, especially $\mathrm{Pb}$ and $\mathrm{Zn}$ which concentration were increased in final value 75 and 80 times compared with initial values, respectively. However, an increase of these two elements in the soil $(\mathrm{Zn}=26$ and $\mathrm{Pb}=71 \mathrm{ppm})$ nearby the pitcher indicate that the used substrates have limitations in absorption capacity for the heavy metals in high concentration of them in the wastewater. As this is related to their surface area, application of a nano form of the substrates such as nano zeolite might remarkably increase their cation exchange capacity and surface area.

Keywords Heavy metal - Industrial wastewater - Zeolite · Perlite $\cdot$ Vermiculite $\cdot$ Esfahan

\section{Introduction}

An international research institute acknowledges the Mediterranean and the Middle East regions are facing a critical water shortage (Yazdanpanah et al. 2014). Therefore, governments and farmers plan to use wastewater for irrigation to reduce the pressure on fresh water resources (Keremane and Mckay 2007; Biswas et al. 2015). In Esfahan region (Iran), municipal (urban) and industrialtreated wastewater are widely used for irrigating agricultural lands especially in fruit and vegetable production.

Besides the use of wastewater for irrigation, efficiency irrigation systems have a high priority for governments and farmers. Pitcher irrigation is a low cost and simple method with high potential of water saving (Abu-Zreig et al. 2006). Combination of pitcher irrigation with treated wastewater resource could be an efficient system to reduce total dissolved elements and treat municipal and industrial 
wastewater (Najafi et al. 2015). However, the mixture of substrates inside the pitchers plays a key role in the success of the combined system.

Zeolite, perlite, and vermiculite as effective and easy heavy metals detox natural minerals can be selected to use as a substrate inside the pitcher. They have selective adsorption, cation exchange capacity, dehydration-rehydration, and catalysis properties that might make them effective in eliminating heavy metals. The most important feature of them in agricultural application is their ion exchange capability without major changes in structure (Mumpton and Fishman 1977; Street 1994). Pb, Cd, and $\mathrm{Hg}$, which are typical toxic heavy metals, could be captured by zeolite (Kazemian et al. 2001; Visa 2016). Absorption of heavy metals from industrial, municipal, and agricultural wastewater by zeolite has been widely studied (Hokkanen et al. 2013; Wen et al. 2016). Tabatabae et al. (2012) studied effect of three types of zeolite with four sizes on adsorption of heavy metals from compost factory leachate. The results showed that $10 \%$ zeolite in the soil had a significant effect on heavy metal absorption. The objective of this study was to assess the performance of a natural zeolite such as clinoptilolite compared to perlite and vermiculite for eliminating heavy metals from industrial wastewater in pitcher irrigation system.

\section{Materials and methods}

\section{Field site characteristics}

The study area is located in the grape garden on the border of Esfahan, Iran $\left(32^{\circ} 44^{\prime} \mathrm{N}, 51^{\circ} 46^{\prime} \mathrm{E}\right.$ and $\left.1517 \mathrm{~m} \mathrm{ASL}\right)$. Esfahan is situated on semi-arid plateau of central Iran, with dry and hot summers and mild winters. Mean annual precipitation is about $110 \mathrm{~mm}$ (2004-2014) and mean annual evapotranspiration is $1547 \mathrm{~mm}$. The soil was clay loam with low amount of organic matter. Chemical properties of soil of experimental field are presented in Table 1.

\section{Experimental setup}

An experiment was conducted with three treatments. The treatments were clay pitcher included natural zeolite [Clinoptilolite (NZ)], Perlite (P), and Vermiculite (V), which filled half of the volume of a clay pitcher with five

Table 1 Chemical properties of soil of experimental field

\begin{tabular}{lllllllll}
\hline Ec $(\mathrm{dS} / \mathrm{m})$ & $\mathrm{pH}$ & \multicolumn{2}{l}{$\left(\mathrm{mg} \mathrm{kg}^{-1}\right)$} & & & & & \\
\cline { 3 - 8 } & & $\mathrm{Fe}$ & $\mathrm{Cu}$ & $\mathrm{Zn}$ & $\mathrm{Mn}$ & $\mathrm{Cr}$ & $\mathrm{Cd}$ & $\mathrm{Pb}$ \\
\hline 4.1 & 7.6 & 4.7 & 0.5 & 0.01 & 2.2 & 1.3 & 2.4 & 2.4 \\
\hline
\end{tabular}

replications for each treatment. Beside each tree, one pitcher was placed at $50 \mathrm{~cm}$ depth. The initial soil sample of each hole was collected and transported in air-tight bags to the laboratory. Drip irrigation system was installed with emitters located inside the pitchers (Fig. 1). The top of the pitchers was closed with plastic caps to prevent dust and insect entering pitcher. The pitchers were irrigated with treated industrial wastewater (Isfahan steel company's wastewater) 60 times (1500 cc per each irrigation event) over a period of 6 months.

\section{Sampling and analysis}

To determine the quality of irrigation water, $20 \mathrm{~mL}$ of farm irrigation water was collected. Afterward, $\mathrm{pH}$ and electrical conductivity (EC) of the samples were immediately determined. The heavy metals' concentrations were determined by an atomic absorption spectrophotometer (PerkinElmer, USA) (Table 2).

To evaluate the effects of treatments on experimental soil, the pitchers were removed and samples were taken from the substrate inside the pitcher and from soil near the wall and bottom of the holes. The samples were transported to the laboratory in air-tight bags, air-dried and sieved through a mesh $(<2 \mathrm{~mm})$, and then sealed in envelopes until analysis. Soil and substrate samples were used to measure heavy metal concentration according to standard procedures (Carter and Gregorich 2006) before and after irrigation with wastewater. The measurement of soil $\mathrm{pH}$ was done by means of a glass electrode and a calomel electrode as reference ( $\mathrm{pH}$ meter). Before the measurements, the $\mathrm{pH}$ meter was calibrated using standard solutions of $\mathrm{pH} 4$ and $\mathrm{pH}$ 7. EC was measured in 1:5 soil-water extract by means of a conductivity meter (Sonme et al. 2008). To determine total concentrations of $\mathrm{Fe}, \mathrm{Cd}, \mathrm{Cr}, \mathrm{Cu}$,

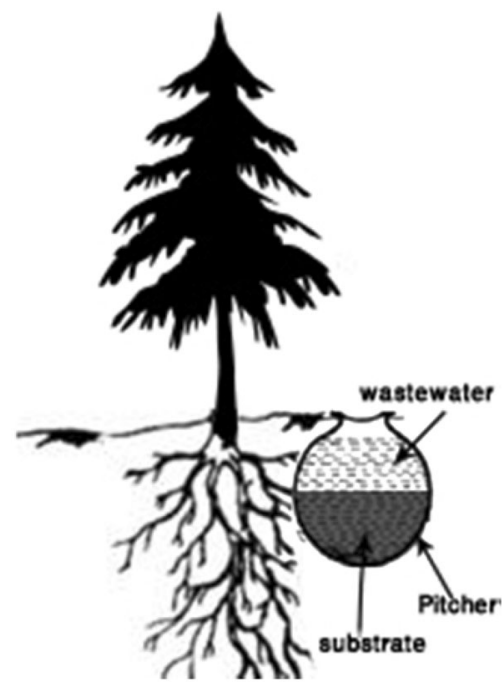

Fig. 1 Diagram of pitcher irrigation 
Table 2 Initial chemical analysis of wastewater

\begin{tabular}{lllllllll}
\hline $\mathrm{pH}$ & $\mathrm{EC}(\mathrm{ds} / \mathrm{m})$ & \multicolumn{2}{l}{$\left(\mathrm{mg} \mathrm{L}^{-1}\right)$} \\
\cline { 3 - 8 } & & $\mathrm{Fe}$ & $\mathrm{Cu}$ & $\mathrm{Zn}$ & $\mathrm{Mn}$ & $\mathrm{Cr}$ & $\mathrm{Cd}$ & $\mathrm{Pb}$ \\
\hline 8.5 & 1.6 & 0.02 & 0.03 & 0.06 & 0.01 & 0.08 & 0.01 & 0.2 \\
\hline
\end{tabular}

$\mathrm{Pb}, \mathrm{Mn}$, and $\mathrm{Zn}$ in the soil, $0.100 \mathrm{~g}$ of dried soil was digested and the elemental concentrations were determined using an atomic absorption spectrophotometer (PerkinElmer, USA). All analyses were repeated three times to minimize the risk of error. The data were statistically analyzed using the package STATISTICA 10 (StatSoft, 2011). Statistical significance was detected using the independent-samples $t$ test and analysis of variance at $\alpha=0.05$.

\section{Results and discussion}

The final concentration of the measured elements in the soil and substrates compared with initial values are shown in Figs. 2, 3. Significant differences were found between initial and final concentration of some of heavy metals $(p<0.05)$ in the soil. Final values of $\mathrm{Fe}, \mathrm{Zn}$, and Mn have no significant differences between soils of different substrates. The concentration of copper in soils treated by zeolite and perlite was higher than vermiculite. Amount of $\mathrm{Cr}$ and $\mathrm{Pb}$ in soils under perlite treatment was lower than zeolite and vermiculite. Figure 2 indicates there are no significant differences between the initial concentration of $\mathrm{Cd}$ in soils treated with Zeolite and Perlite compared with the final concentration of $\mathrm{Cd}$ at the end of experiment period. It is while, the concentration of Cd significantly increased in soils treated by vermiculite compared with initial concentration.

Significant differences were found between initial and final concentration of heavy metals except for $\mathrm{Cu}$ and $\mathrm{Mn}$ $(p<0.05)$ in the substrates. The results showed that zeolite could absorb more Fe compared to perlite and vermiculite but vermiculite has ability to absorb more $\mathrm{Cr}$ and $\mathrm{Zn}$ compared to zeolite and perlite. The results also show that zeolite and perlite have higher capability to absorb $\mathrm{Cd}$ and $\mathrm{Pb}$ than zeolite.

Percentage of removal of elements in soil and substrate were presented in Table 3. The results showed that $\mathrm{Zn}$ and $\mathrm{Mn}$ have highest and lowest range of removal percentage among the measured elements, respectively.

Based on aforementioned results, it was determined that after six months of continued irrigation with industrial wastewater, cumulative amounts of $\mathrm{Zn}$ and $\mathrm{Pb}$ were perceptibly increased in the substrates, same results are reported by Erdem et al. (2004) which show natural zeolites have great potential to remove heavy metal species $(\mathrm{Cu} 2+, \mathrm{Zn} 2+$ and $\mathrm{Mn} 2+$ ) from industrial wastewater. Absorption of $\mathrm{Zn}$ in vermiculite was significantly higher than other substrates, whereas natural zeolite and perlite showed almost the same values. Unlike vermiculite, high $\mathrm{Pb}$ elimination from the industrial wastewater was resulted in natural zeolite and perlite substrates. This is supported by findings of Halimoon and Yin (2010) and Medvidović et al. (2006) which showed zeolite has high performance to remove heavy metals from wastewater. Natural zeolite also showed medium ability to absorb $\mathrm{Fe}$ and $\mathrm{Cd}$ from wastewater, so, high amounts of these elements are accumulated in the soil surrounding the pitcher. Zeolite, vermiculite, and perlite showed no capability of $\mathrm{Cu}$,
Fig. 2 Initial and final concentration of elements in soils. In each Column, unsimilar letters indicate significant difference $(p<0.05)$.

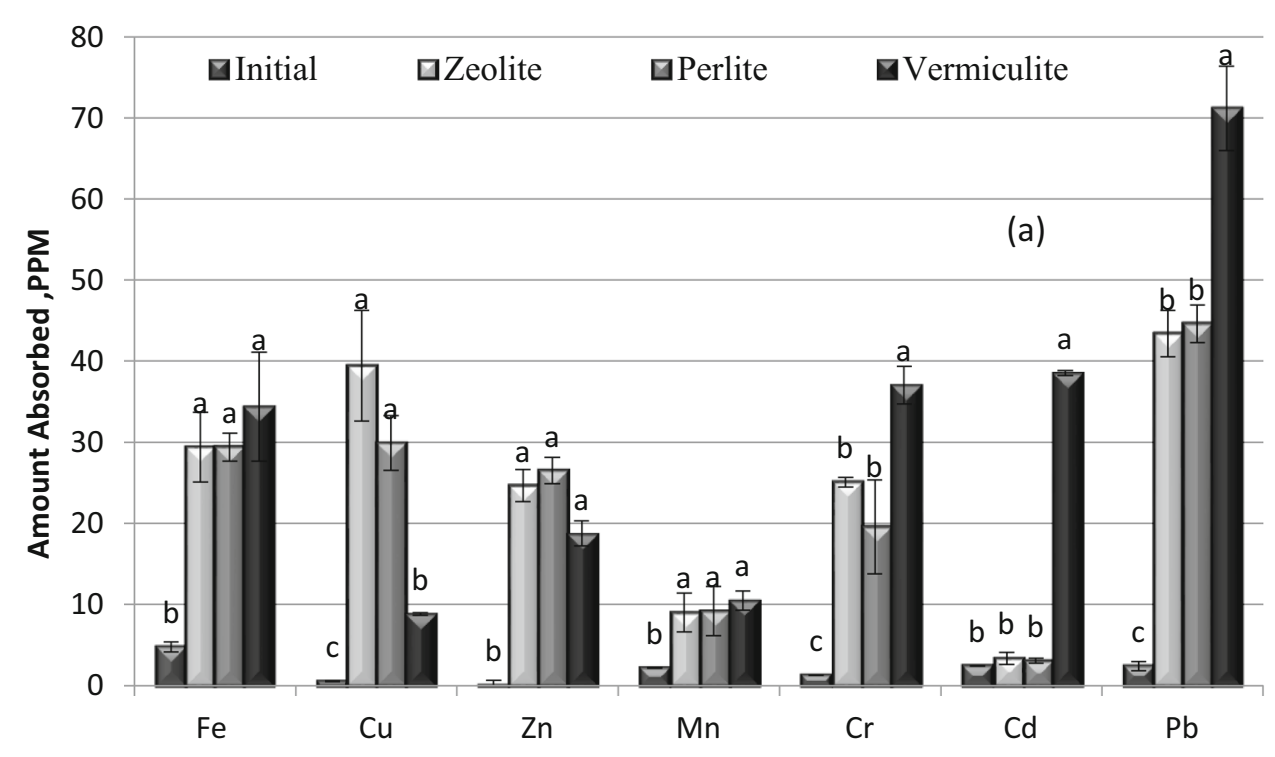


Fig. 3 Initial and final concentration of elements in substrates. In each Column, unsimilar letters indicate significant difference $(p<0.05)$.

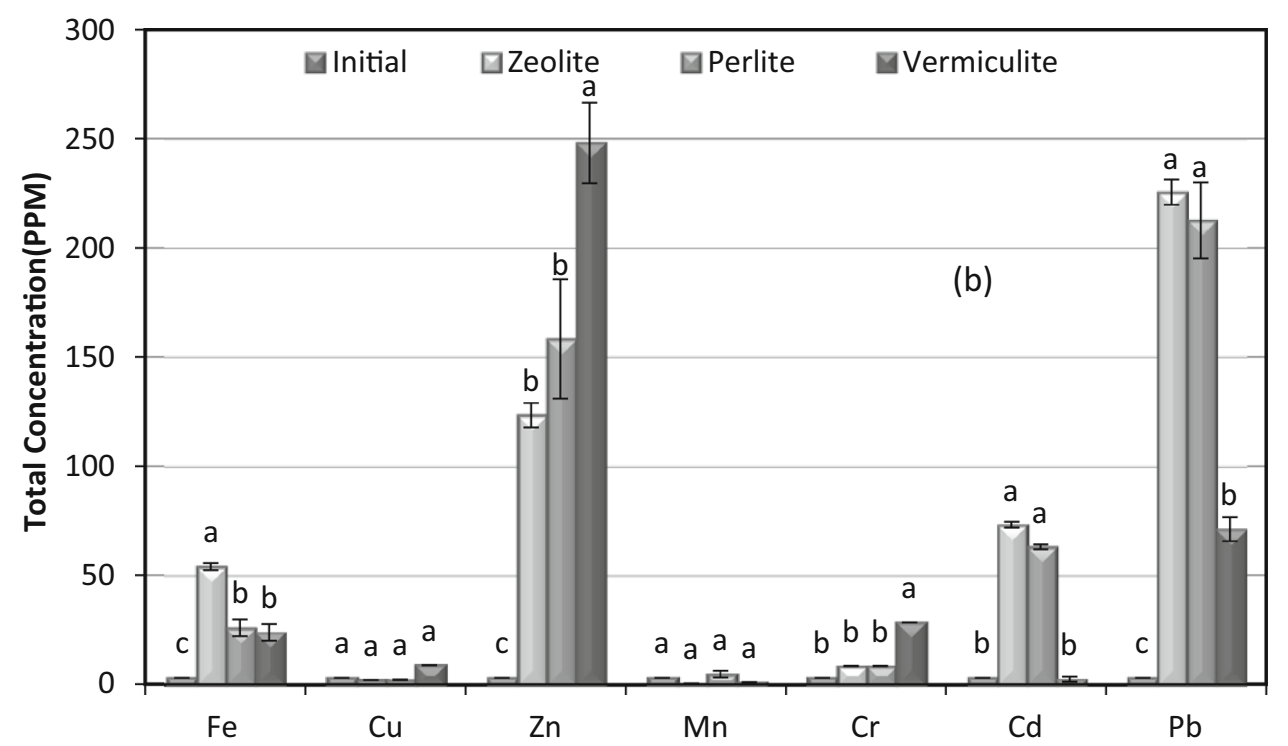

\begin{tabular}{lrrrrrrr}
\hline Substrate & $\mathrm{Fe}(\%)$ & $\mathrm{Cu}(\%)$ & $\mathrm{Zn}(\%)$ & $\mathrm{Mn}(\%)$ & $\mathrm{Cr}(\%)$ & $\mathrm{Cd}(\%)$ & $\mathrm{Pb}(\%)$ \\
\hline Zeolite & & & & & & & \\
$\quad$ Soil & 516 & 7449 & 246,738 & 308 & 1832 & 39 & 1698 \\
$\quad$ Substrate & 1698 & -33 & 4012 & -92 & 179 & 2339 & 7416 \\
Perlite & & & & & & & \\
$\quad$ Soil & 516 & 5625 & 265,280 & 318 & 1405 & 27 & 1750 \\
Substrate & 763 & -32 & 5176 & 57 & 179 & 2003 & 6986 \\
Vermiculite & & & & & & & \\
$\quad$ Soil & 621 & 1586 & 187,400 & 375 & 2752 & 1490 & 2850 \\
Substrate & 694 & 194 & 8169 & -70 & 847 & -20 & 2272 \\
\hline
\end{tabular}

Table 3 Percentage of removal of elements in soil and substrate
$\mathrm{Mn}$, and $\mathrm{Cr}$ filtration. The same results were reported by Erdem et al. (2004).

\section{Conclusion}

Several studies reported that irrigation of agricultural lands with wastewater has caused a substantial accumulation of heavy metals in soils compared to background values and control soils. In spite of the fact that the used substrates in this experiment have high ability to absorb some elements, especially $\mathrm{Pb}$ and $\mathrm{Zn}$, an increase of these two elements in the soil near the pitcher indicates that the used substrates have limitations in absorption capacity for the heavy metal. This result could be related to small surface area of these materials. The application of a Nano form of these substrates such as Nano-zeolite might remarkably increase their cation exchange capacity and surface area, however, $\mathrm{pH}$ and reducing conditions can influence distribution of soluble metals and they should be assessed in future works.
Open Access This article is distributed under the terms of the Creative Commons Attribution 4.0 International License (http://crea tivecommons.org/licenses/by/4.0/), which permits unrestricted use, distribution, and reproduction in any medium, provided you give appropriate credit to the original author(s) and the source, provide a link to the Creative Commons license, and indicate if changes were made.

\section{References}

Abu-Zreig M, Abe Y, Isoda H (2006) The auto-regulative capability of pitcher irrigation system. Agric Water Manag 85(3):272-278

Biswas GC, Sarkar A, Rashid H, Shohan MH, Islam M, Wang Q (2015) Assessment of the irrigation feasibility of low-cost filtered municipal wastewater for red amaranth (Amaranthus tricolor L cv. Surma). Int Soil Water Conserv Res 3(3):239-252

Carter MR, Gregorich EG (2006) Soil sampling and methods of analysis. Canadian Society of Soil Science, Taylor \& Francis Group, LLC., p 200

Erdem E, Karapinar N, Donat R (2004) The removal of heavy metal cations by natural zeolites. J Coll Interf Sci 280:309-314

Halimoon N, Yin RGS (2010) Removal of heavy metals from textile wastewater using zeolite. Env Asia 3(special issue):124-130 
Hokkanen S, Repo E, Sillanpää M (2013) Removal of heavy metals from aqueous solutions by succinic anhydride modified mercerized nanocellulose. Chem Eng J 223:40-47

Kazemian H, Rajec P, Macasek F, Kufcakova J (2001) Investigation of lead removal from wastewater by Iranian natural zeolites using radio analytical methods. Stud Surf Sci Catal 135:369

Keremane GB, McKay J (2007) Successful wastewater reuse scheme and sustainable development: a case study in Adelaide'. Water Env J. 21:83-91

Medvidović NV, Perić J, Trgo M (2006) Column performance in lead removal from aqueous solutions by fixed bed of natural zeoliteclinoptilolite. Sep Purif Technol 49:237-244

Mumpton FA, Fishman PH (1977) The application of natural zeolites in animal science and aquaculture. J Anim Sci 45:1188-1203

Najafi P, Shams J, Shams A (2015) The effects of irrigation methods on some of soil and plant microbial indices using treated municipal wastewater. Int J Recycl Org Waste Agric 4(1):63-65

Sonme ZS, Buyuktas D, Okturen F, Citak S (2008) Assessment of different soil to water ratios $(1: 1,1: 2.5,1: 5)$ in soil salinity studies. Geoderma 144:361-369
StatSoft I (2011) STATISTICA (data analysis software system), version 10. http://www.statsoft.com

Street C (1994) Natural zeolites in animal feeds. Feed Compounder. (February)

Tabatabae SH, Najafi P, Mirzaei SM, Nazem Z, Heidarpour M, Hajrasoliha S, Afyuni M, Harchegani H, Landi E, Akasheh L, Zamanian M, Barani M, Amini H (2012) Compost' leachate recycling through land treatment and application of natural Zeolite. Int J Recycl Org Waste Agric 1:2

Visa M (2016) Synthesis and characterization of new zeolite materials obtained from fly ash for heavy metals removal in advanced wastewater treatment. Powder Technol 294:338-347

Wen J, Yi Y, Zeng G (2016) Effects of modified zeolite on the removal and stabilization of heavy metals in contaminated lake sediment using BCR sequential extraction. J Environ Manage 178:63-69

Yazdanpanah M, Hayati D, Hochrainer-Stigler S, Zamani GH (2014) Understanding farmers' intention and behavior regarding water conservation in the Middle-East and North Africa: a case study in Iran. J Environ Manage 135:63-72 